\title{
Climate change, climate justice and the application of probabilistic event attribution to summer heat extremes in the California Central Valley
}

\author{
Roberto Mera $^{1,2} \cdot$ Neil Massey $^{3} \cdot$ David E. Rupp $^{1}$ • \\ Philip Mote $^{1} \cdot$ Myles Allen $^{3,4} \cdot$ Peter C. Frumhoff $^{5}$
}

Received: 1 August 2014 / Accepted: 25 July 2015 /Published online: 7 August 2015

(C) The Author(s) 2015. This article is published with open access at Springerlink.com

\begin{abstract}
Probabilistic event attribution (PEA) is an important tool for assessing the contribution of climate change to extreme weather events. Here, PEA is applied to explore the climate attribution of recent extreme heat events in California's Central Valley. Heat waves have become progressively more severe due to increasing relative humidity and nighttime temperatures, which increases the health risks of exposed communities, especially Latino farmworkers and other socioeconomically disadvantaged communities. Using a superensemble of simulations with the Hadley Centre Regional Model (HadRM3P), we find that (1) simulations of the hottest summer days during the 2000s were twice as likely to occur using observed levels of greenhouse gases than in a counterfactual world without major human activities, suggesting a strong relationship between heat extremes and the increase in human emissions of greenhouse gases, (2) detrimental impacts of heat on public health-relevant variables, such as the number of days above $40{ }^{\circ} \mathrm{C}$, can be quantified and attributed to human
\end{abstract}

This article is part of a Special Issue on "Climate Justice in Interdisciplinary Research" edited by Christian Huggel, Markus Ohndorf, Dominic Roser, and Ivo Wallimann-Helmer. This paper is linked to the following contribution of this special issue: Thompson and Otto, doi 10.1007/s10584-015-1433-Z

Electronic supplementary material The online version of this article (doi:10.1007/s10584-015-1474-3) contains supplementary material, which is available to authorized users.

Roberto Mera

rmera@ucsusa.org

1 Oregon Climate Change Research Institute, College of Earth, Ocean and Atmospheric Sciences, Oregon State University, Corvallis, OR 97331, USA

2 Union of Concerned Scientists, 1825 K Street NW, Suite 800, Washington, DC 20006, USA

3 Environmental Change Institute, Oxford University, South Parks Road, Oxford OX1 3QY, UK

4 Department of Atmospheric, Oceanic, and Planetary Physics, Oxford University, Oxford OX1 3QY, UK

5 Union of Concerned Scientists, 2 Brattle Square, Cambridge, MA 02238, USA 
activities using PEA, and (3) PEA can serve as a tool for addressing climate justice concerns of populations within developed nations who are disproportionately exposed to climate risks.

\section{Introduction}

Recent advances in probabilistic event attribution (PEA) have allowed for enhanced exploration of the role of human activities in meteorological extremes (Otto et al. 2013; Pall et al. 2011; Rupp et al. 2015). PEA can be applied within the context of addressing inequities in the human costs of climate change given its ability to provide fractional attribution of an event (James et al. 2014; Thompson and Otto 2015). For example, recent attribution research on record-breaking heat extremes in Russia (Otto et al. 2013), southeast Europe (Sippel and Otto 2014) and Texas (Rupp et al. 2015) focus on regions and populations that were ill-prepared for these extremes, experiencing both heat-health impacts and losses in agricultural productivity.

Thompson and Otto (2015) argue that the ability to attribute extreme weather events to climate change through PEA is germane to climate policy discussions over the relative responsibilities of nations for climate loss and damage. The impacts of climate change are also distributed inequitably within nations, including developed nations. For instance, heat extremes in the United States disproportionately affect specific populations, including those in urban areas (Fischer et al. 2012), areas lacking air conditioning (O'Neill et al. 2005), lower economic background (Hajat and Kosatky 2010), elderly, and specific ethnic groups (White-Newsome et al. 2009). These factors need to be taken into consideration when exploring the human impact of heat extremes in order to inform policy-makers and affected communities where a case can be made for lack of preparation and adaptation. Currently, a large fraction of the population in the United States is inadequately prepared for extreme heat (White-Newsome et al. 2014).

In California's Central Valley, heat waves have become progressively more severe in recent decades due to higher humidity and warmer nighttime temperatures (Gershunov et al. 2009). For example, a particularly severe heat wave in 2006 was linked with increases in emergency department visits and hospitalizations (Knowlton et al. 2009) and at least 146 deaths (California Department of Health Services 2007). Among the most affected was the Latino community in agricultural regions (Knowlton et al. 2009), who face relatively high exposure to extreme heat due to extensive outdoor work. In fact, the Latino population continues to be at disproportionately high climate risk across the United States, supporting the relatively wide sentiment within the Latino community that climate change is a serious problem that should be addressed (Leiserowitz and Akerlof 2010).

Allen (2003) introduced the notion of utilizing fractional attribution and posed an interesting question: should society hold certain non-state entities, such as major industrial emitters or producers of carbon, accountable for losses and damages incurred by climate change? James et al. (2014) argued that PEA could be relevant to the questions of international responsibility for loss and damage associated with extreme events affecting developing nations. Here it is argued that PEA can also be applied to address the climate justice concerns of populations within developed nations who are disproportionately exposed to climate risks. Thus, this study focuses on variables relevant to the public health impacts of extreme heat in the California Central Valley to highlight the applicability of PEA to inform decision makers and affected communities on key questions: are these events, and their associated impacts, increasing in intensity and is climate change a major driver? 
Variables examined include the total number of days in a month with maximum temperatures exceeding $40.6{ }^{\circ} \mathrm{C}$ (Luber and McGeehin 2008), heat stress due to high relative humidity (Knowlton et al. 2009) and nighttime temperatures (Kalkstein et al. 1996; Greene and Kalkstein 1996). Heat stress has been found to be especially important in terms of societal impact in recent studies (Mastrangelo et al. 2006) and has been applied within the context of PEA (Sippel and Otto 2014).

Climate modeling with very large ensembles provides the framework for PEA in the present work. A large number of simulations allows for a high number of samples in the tails of the distributions of the variables of interest, thus facilitating the robust determination of spatio-temporal changes in rare events (Mote et al. 2015).

\section{Material and methods}

This study analyzes June, July and August (JJA) daily maximum and minimum temperature observations from 39 U.S. Historical Climatology Network (USHCN) stations Version 2 (Menne et al. 2009) within the states of California and Nevada since the year 1900. A total of 30 stations have weather records in the Central Valley since at least 1961 (Kunkel et al. 2008).

For public health indicators, a temperature of $40.6{ }^{\circ} \mathrm{C}$ provides an appropriate measure since it is a threshold that defines heat stroke and may contribute to mortality if the core temperature of the individual is measured at or above this level (Luber and McGeehin 2008). Also, as a proxy for heat stress due to high relative humidity, this study employs a simplified wet-bulb globe temperature (WBGT). This is explored in the supplementary materials.

In order to quantify the climate attribution of extreme heat events in the model analysis, this study uses the fraction of attributable risk (FAR), defined as the fraction of the current risk that is attributable to past greenhouse gas (GHG) emissions (Allen 2003), and is computed as follows:

$$
\mathrm{FAR}=1-\mathrm{P} 0 / \mathrm{P} 1
$$

Such that P1 is the probability of a climatic event occurring in the presence of anthropogenic forcing of the climate system, and $\mathrm{P} 0$ is the probability of it occurring in the absence of anthropogenic forcing.

\subsection{Model analysis}

The capability to generate a very large number of simulations is provided by the weather@home experiment, a public volunteer-distributed computing project for simulating regional climate (Allen 1999; Massey et al. 2014). Weather@home uses the Hadley Centre Atmospheric General Circulation Model 3P (HadAM3P; $1.875^{\circ}$ x 1.25, 19 levels; Jones et al. 2004) atmosphere-only global climate model (AGCM) and a regional climate model (RCM) variant, HadRM3P, set at a 25-km horizontal resolution, nested within the AGCM (Mote et al. 2015).

Three sets of simulations were carried out to address (a) the decadal differences in temperature found in the observations, and (b) to explore whether climate change is a major driver of the increase in intensity of heat waves during the 2000s. The influence of year-to-year SST-driven internal variability on the region's summer temperatures is addressed when comparing an all-forcings scenario in which SSTs, sea ice fractions, and forcings are set to 
observed values against a scenario devoid of much of the anthropogenic GHG emissions ("Natural" forcings). This is because the Natural simulation SST anomalies still maintain much of the same spatial patterns and spatial gradients as in the all-forcimgs scenario, even though each set of Natural experiment SSTs have had an anthropogenic warming pattern removed from them.

The simulations carried out in this experiment varied by their prescribed boundary conditions [i.e., sea surface temperature (SST) and sea ice fraction] and their anthropogenic and natural forcings. Forcings include well-mixed greenhouse gases, volcanic and solar forcing, as well as aerosols and land use.

In the first set of simulations, which we call the "All forcings 1" (hereafter AF1) scenario, SSTs, sea ice fractions, and forcings were set to observed values during the period 1961-2010. SST and sea ice were derived from the monthly HadISST (Rayner et al. 2003) gridded observational dataset. An ensemble of 450 simulations per year was generated by varying the initial conditions in each year for each simulated year (details on how the initial conditions were generated is given Massey et al. 2014).

In the second set of simulations, the "All forcings 2" (AF2) scenario, SSTs, sea ice fractions, and forcings were also set to observed values, but the period was limited to 20012010. SST and sea ice were derived from the 5-day OSTIA (Donlon et al. 2011) gridded observational datasets. An ensemble of 350 simulations per year was generated by varying the initial conditions of each year. This set of simulations was created to provide higher temporal resolution (daily) in the output and to take advantage of higher temporal resolution found in OSTIA.

The third set of simulations - the "Natural" scenario - mimicked the second scenario, except that SST, sea ice fraction, and anthropogenic forcings (anthropogenic GHGs and aerosols) were set to values representative of the year 1900. "Natural" SSTs were based on patterns of SST changes from 4 Coupled Model Intercomparison Project Phase 5 (CMIP5) GCMs: HadGEM2-ES, CNRM-CM5, GFDL-ESM2M and GISS-E2-H. Filtered changes in SSTs from each of these GCMs between the CMIP5 historicalNat (natural forcings only) experiment and the CMIP5 historical (natural and anthropogenic forcings) experiment were added to the OSTIA SSTs using the same approach as Schaller et al. (2014). For sea ice fraction, we used the years in the OSTIA record (1985-2010) with the largest mean annual Arctic and Antarctic sea ice extents: 1987 and 2008, respectively (Schaller et al. 2014).

Unlike in AF1, in the AF2 and Natural experiments, daily maximum and minimum temperature were archived for each day of the year, which permited the calculation of Tmin_hi; this is advantageous for the analysis given its increased role in recent heat extremes (Gershunov et al. 2009). AF1 has 5-day intervals of specific humidity, allowing for analysis of $W B G T$ in the supplementary materials.

HadRM3P run over the Western US domain was initially configured and tested for the Pacific Northwest for the years 2003-2007 (Zhang et al. 2009) and analyzed for extreme events in Dulière et al. (2011), while a brief evaluation of HadRM3P runs within the weather@home system is given in Mote et al. (2015). Additional model evaluation for the Western US and CA/NV from experiment AF1 is provided in the supplementary materials of this paper.

HadAM3P is able to reproduce the reanalysis-based large-scale meteorological conditions associated with temperature fluctuations as represented by spatial patterns of the correlation between geopotential height and western US-averaged summer temperature (Supplementary Fig. 1). When compared to station observations in the regional domain (Supplementary Fig. 2), 
HadRM3P has positive biases for all temperature variables (Supplementary Table 1). However, the spatial correlations of HadRM3P with observations are higher than the correlations of reanalysis with observations, consistent with findings by Dulière et al. (2011).

Given that both the observational and modeled frequency distributions of temperature are approximately normal, the bias in the modeled output is removed using a simple mean and variance technique (Massey et al. 2012; Sippel and Otto 2014), where the bias-removed model output $\left(M O D^{\prime}\right)$ is calculated as:

$$
M O D^{\prime}=\frac{M O D-\mu M O D}{\sigma M O D} \sigma O B S+\mu O B S
$$

where $M O D$ is the modeled output and $\mu M O D, \sigma M O D$ and $\mu O B S, \sigma O B S$ are the mean $(\mu)$ and standard deviation $(\sigma)$ of the non-parametric modeled and observed distributions, respectively.

\section{Results}

\subsection{Decadal temperature anomalies in the observations}

The present study examines a comprehensive record of observed temperature extremes dating back to 1900 for validation and bias-correction of the superensemble model results. It includes the lowest (Tmin_lo) and highest daily minimum (Tmin_hi), as well as the highest (Tmax_hi) and lowest daily maximum (Tmax_lo) for the summer months of June-July-August (JJA). This analysis serves as a baseline for exploring heat metrics relevant to public health..

Long-term trends are evaluated for the 1900-2010 period for California and Nevada combined $(\mathrm{CA} / \mathrm{NV})$, bounded by $32.5-42^{\circ} \mathrm{N}$ and $125-114^{\circ} \mathrm{W}$, for 39 stations with continuous records since 1900 (Fig. 1). This domain is chosen because of its general spatial coherence in terms of its summer climatology at lower elevations and because it has been analyzed extensively in the literature (Gershunov et al. 2009; Walsh et al. 2014). Decadal anomalies are calculated as the differences from the mean over the period 1901-1960.

The CA/NV domain's JJA Tmax_hi (Fig. 1a, red bars) had its highest positive anomaly in the $1930 \mathrm{~s}\left(+0.85{ }^{\circ} \mathrm{C}\right.$ above the mean of $\left.37.6^{\circ} \mathrm{C}\right)$, followed by the $1920 \mathrm{~s}$. These positive
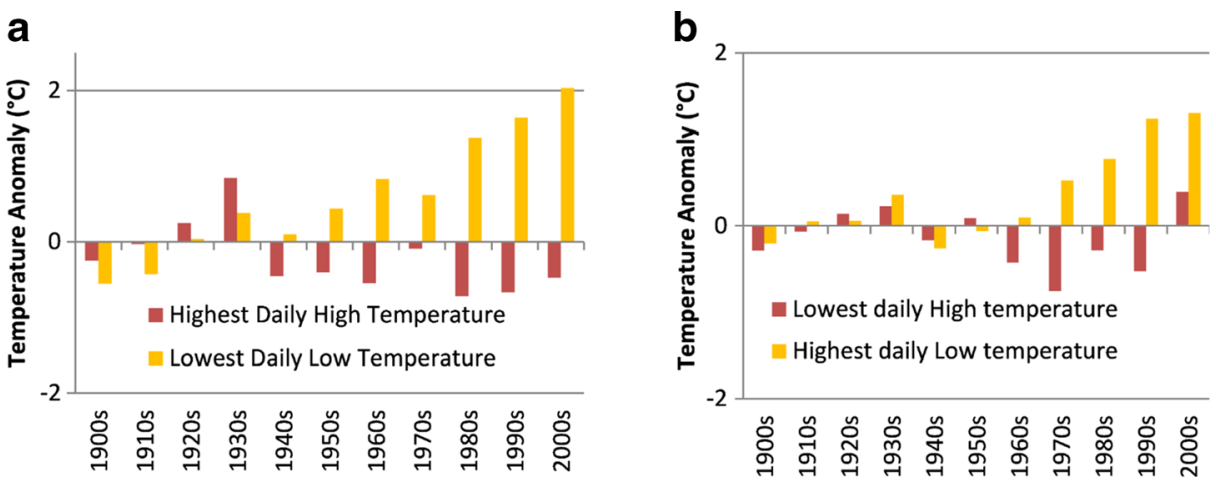

Fig. 1 Decadal averages of temperature anomalies relative to the 1901-1960 JJA average for California/Nevada for (a) the highest daily maximum (red) and lowest daily minimum (yellow) temperatures and (b) lowest daily maximum (red) and highest daily minimum (yellow) in a month 
anomalies in the earlier part of the 20th century were a result of a severe multi-year drought, which, combined with harmful land-use practices (Cook et al. 2009), caused a depletion of soil moisture and reduction of the temperature-moderating effects of evaporation (Kunkel et al. 2008). Since then, the data show no strong temporal trend in Tmax_hi. In contrast, Tmin_lo (yellow bars) has been, in general, increasing since the $1940 \mathrm{~s}$, peaking at a positive decadal anomaly of $2.03{ }^{\circ} \mathrm{C}$ in the 2000 s (above the mean of $7.35^{\circ} \mathrm{C}$ ). The increases in Tmin lo with little change in Tmax_hi imply a reduction in the observed diurnal range.

Tmax_lo (Fig. 1b) during the 2000s surpasses the baseline mean $23.4{ }^{\circ} \mathrm{C}$ by $0.4{ }^{\circ} \mathrm{C}$ and is higher than the 1930s. Interestingly, Tmax_lo shows strong negative values for the 1960s1990s period, hinting at other mechanisms not addressed here. Tmin hi $\left(+1.3{ }^{\circ} \mathrm{C}\right.$ above the mean of $16.85^{\circ} \mathrm{C}$ ) echoes the robust warming seen by Gershunov et al. (2009) and Bumbaco et al. (2013) in nighttime minima. The same analysis for Tmin_hi over Central Valley stations (not shown) shows a $1.5^{\circ} \mathrm{C}$ rise in the warmest nights in the 2000 s to a temperature of $23.2^{\circ} \mathrm{C}$ for the decadal average for July.

In summary, the observational record shows an increase in nighttime temperature in the region; higher nighttime temperatures provide less temporary relief during multi-day heat waves. This has serious health implications for socieconomically disadvantaged communities where central air conditioning, found to be a major factor in reducing heat-related mortality (O’Neill et al. 2005), may not be affordable.

\subsection{Decadal comparisons in the model}

Model simulations for the decade of the 2000s are compared against the 1960s in order to investigate the roles of SST-imposed variability as well a rising levels of GHGs on summer temperature extremes. Bias correction is employed for the Tmax_hi and Tmin_lo variables to address biases in the model.

figure 2 a shows return periods, an estimate of the likelihood of an event to occur, for Tmax_hi. The data is derived from area averages of Tmax_hi for gridpoints over 30 stations the Central Valley for the 2000s and 1960s. Each dot in the curve represents a single model simulation, while the hatchings show bootstrapped inner $95 \%$ percentile uncertainty ranges. Here, Tmax_hi is $0.66{ }^{\circ} \mathrm{C}$ warmer in the 2000 s for $10-100$ year return periods. This suggests that very warm days expected to occur every 100 years during the 1960 s were twice as likely to occur on any given year during the 2000s. Bias correction addresses the warm bias displayed in model results, bringing them closer to observed values from 30 weather stations in the Central Valley. The bias-corrected output shows Tmax_hi (Fig. 2b) is $0.46{ }^{\circ} \mathrm{C}$ warmer for the same average of return periods. This is important because it suggests that the differences between the two decades may not be as large when the warm bias is accounted for.

There is a smaller margin in the distribution for Tmin_lo (Fig. 2c) between the two decades analyzed compared to Tmax_hi. In the case of Tmin_lo, the $2000 \mathrm{~s}$ are, on average, $0.46{ }^{\circ} \mathrm{C}$ warmer than the 1960 s for return periods ranging from 10 to 100 years. When bias correction is applied the margin is only slightly smaller, with a $0.44{ }^{\circ} \mathrm{C}$ difference, implying a more uniform rise in temperature for both high maxima and low minima. Interestingly, when the area average of Tmin_lo is widened to the CA/NV domain (Supplementary Figure 7), the change in return periods between 10 and 100 years is $0.95{ }^{\circ} \mathrm{C}$ without bias correction while Tmax_hi is $0.61{ }^{\circ} \mathrm{C}$. This suggests that other areas of California and Nevada have seen warmer nights than days, consistent with the observations of the CA/NV domain used in Fig. 1 and the extensive analysis on public health impacts carried out by Knowlton et al. (2009) and Guirguis 

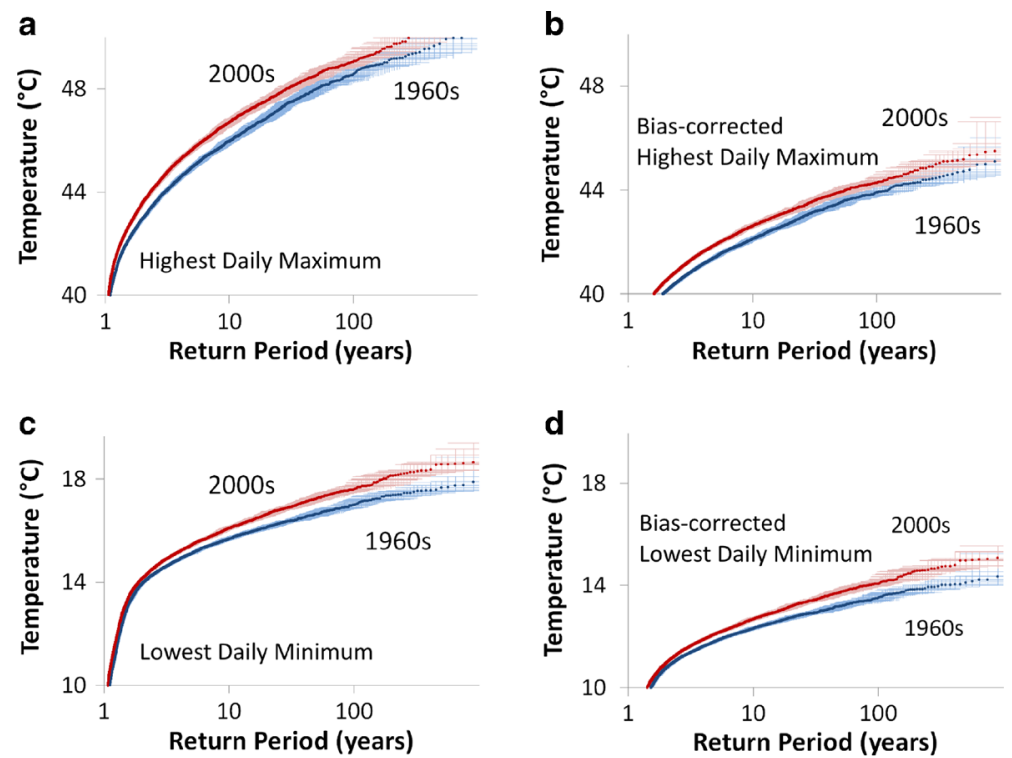

Fig. 2 Return periods of 2000s versus 1960s comparisons for California's Central Valley for (a) Tmax_hi $\left({ }^{\circ} \mathrm{C}\right)$ (b) bias-corrected Tmax_hi, (c) Tmin_lo $\left({ }^{\circ} \mathrm{C}\right)$ and (d) bias-corrected Tmin_lo using All forcings (AF1) simulations. Hatchings show bootstrapped inner $95 \%$ percentile uncertainty ranges

et al. (2014). The exposure and vulnerability of inhabitants to extreme heat in the more temperate areas like San Francisco presents new problems that must be addressed by policymakers in the region.

\subsection{Attribution of trends}

Assessing the impact of climatic and other drivers of change requires a multi-disciplinary approach for careful attribution research (Huggel et al. 2013; Hansen et al. 2015). Here we first present the climate results from the simulations and then focus on trends most relevant for public health risks associated with extreme heat.

Internal variability stemming from dominant SST modes has an important impact on Western US climate (Wang et al. 2013). However, we did not screen years based on tropical Pacific SSTs because major heat waves have occurred during all phases of the El NiñoSouthern Oscillation (see Gershunov et al. 2009).

Both Tmax_hi and Tmin_hi are higher for AF2 than the Natural simulations (Fig. 3). The change in Tmin_hi (Fig. 3b) is greater than the change in Tmax_hi (Fig. 3a) for the 10100 year return period average from the Natural to the AF2 experiment: $1{ }^{\circ} \mathrm{C}$ warmer for Tmin_hi and $0.75{ }^{\circ} \mathrm{C}$ warmer for Tmax_hi, respectively. Here, bias correction is also applied. We argue that what is being addressed in this instance is structural bias in the model and not to forcing biases from the SSTs or GHGs. For the bias-corrected Tmax hi (Fig. 3b), AF2 is $0.21{ }^{\circ} \mathrm{C}$ warmer than Natural for $10-100$ year return period average. For bias-corrected Tmin_hi (Fig. 3d), AF2 is 0.59 warmer than Natural.

Unlike simulations in AF1 comparing the 1960s and 2000s, where the change in Tmax_hi was higher than Tmin_lo (Fig. 2), AF2 vs Natural (Fig. 3) is closer to observations. This may 

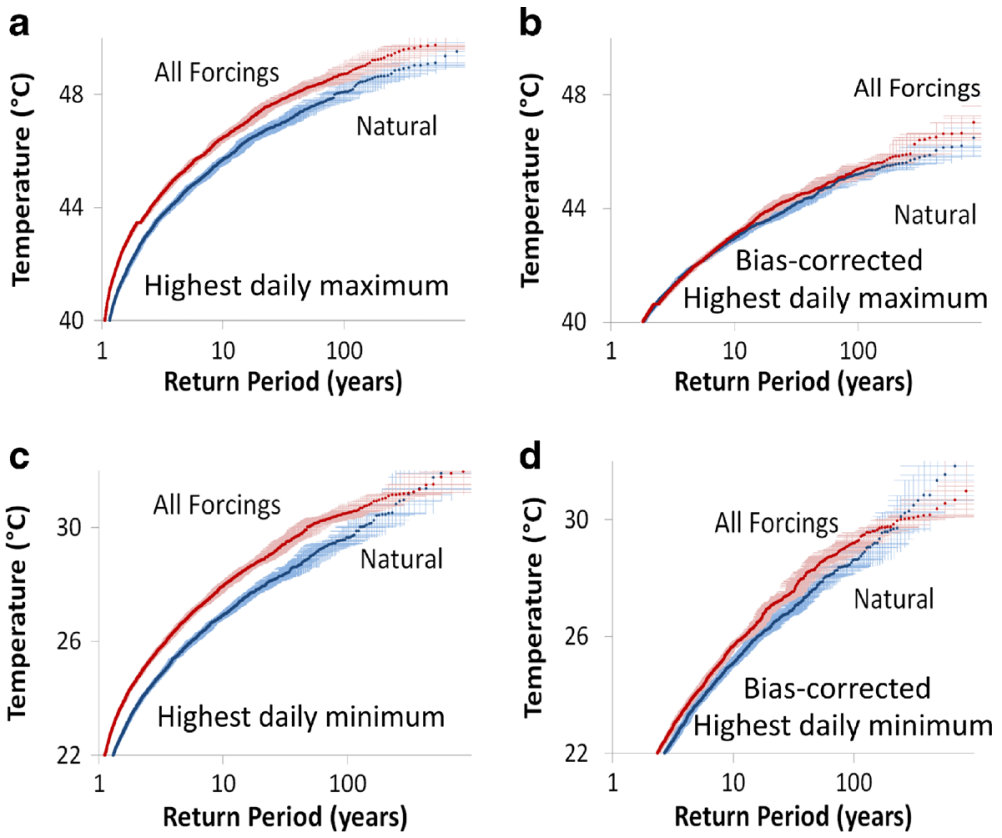

Fig. 3 Return periods of (a) Tmax_hi, (b) bias-corrected Tmax_hi, (c) Tmin_hi and (d) bias-corrected Tmin_hi simulated temperature of the summer (JJA) for California's Central Valley during the decades of the 2000s from the All forcings (AF2) and Natural simulations. Hatchings show bootstrapped inner $95 \%$ percentile uncertainty ranges

be due to the impact of natural variability, which is circumvented through the use of Natural runs, thereby isolating the influence of GHGs on nighttime temperatures. It should also be noted that both Tmin_lo and Tmin_hi had very similar trends and magnitude of change in the observations (Fig. 1), and AF2 vs Natural also show Tmin_lo (not shown) has as wide a gap as Tmin hi in the return periods.

While model results for Tmin_hi largely reflect the trends found in the observations (Fig. 1b), there is inconsistency with the Tmax_hi variable (Fig. 1a). The model shows a warming trend while the observations suggest no trend. A study of global models displayed more consistency among models in capturing the observed rise in minimum temperatures than maximum temperatures (Lobell et al. 2007). The authors argued that model differences in cloud changes, which affect maximum temperatures more than minima during the summer, were the main source of uncertainty. It is possible that this may account for the disparity between Tmax_hi in the weather@home output and station observations in the Central Valley.

\subsection{Impact on health sector}

To more explicitly consider the impact of observed climate change on heat-health risks to vulnerable populations, PEA is used to assess changes in the probability of days exceeding $40{ }^{\circ} \mathrm{C}$, a proxy for increasing heat stress in the California Central Valley. In Fig. 4a, AF2 is plotted versus Natural runs for the total number of days with maximum temperatures exceeding $40{ }^{\circ} \mathrm{C}$ in a month within the Central Valley, where a 100 -year return period event of 13 days (not necessarily consecutive) above $40{ }^{\circ} \mathrm{C}$ in the Natural experiment is more than 

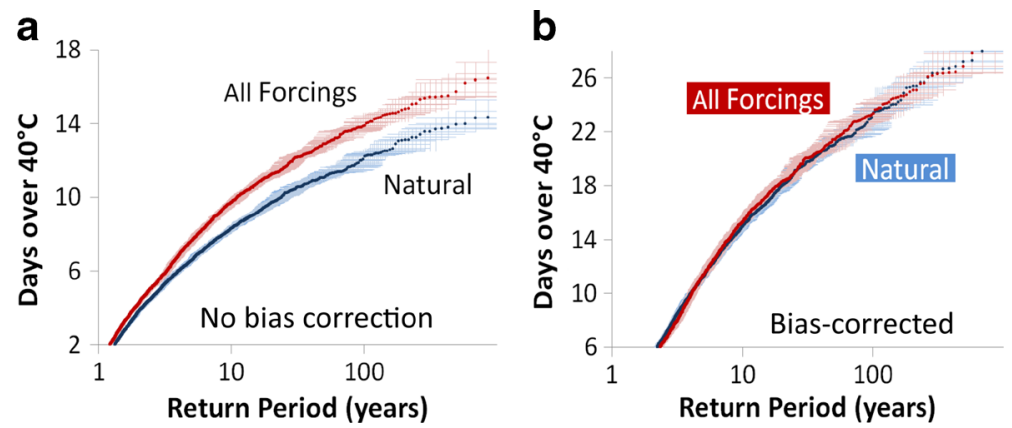

Fig. 4 (a) Return periods of All Forcings AF2 experiment (red) versus Natural (blue) for the total number of days with maximum temperatures exceeding $40^{\circ} \mathrm{C}$, calculated from the mean of area averages over 30 stations in the Central Valley. (b) Return periods for bias-corrected days exceeding $40{ }^{\circ} \mathrm{C}$. Hatchings show bootstrapped inner $95 \%$ percentile uncertainty ranges

twice as likely to occur in AF2, corresponding to a fraction of attributable risk (FAR) of 0.67. That is, anthropogenic greenhouse gas emissions doubled the chances that California's Central Valley experienced the heat extremes observed during the 2000s.

When bias correction is applied to days exceeding $40{ }^{\circ} \mathrm{C}$ (Fig. $4 \mathrm{~b}$ ), the return periods are much warmer due to a higher average for the observations $\left(5.13{ }^{\circ} \mathrm{C}\right.$ compared to $4.93{ }^{\circ} \mathrm{C}$ for AF2 and $4.24{ }^{\circ} \mathrm{C}$ for Natural) and higher standard deviation $\left(5.62{ }^{\circ} \mathrm{C}\right.$ compared to $3.22{ }^{\circ} \mathrm{C}$ for AF2 and $2.86^{\circ} \mathrm{C}$ for Natural). However, analysis of the bias-corrected data shows that AF2 is 0.32 days above Natural for the 10-100 year return average, while uncorrected data is 1.57 days, consistent with preceding analysis for other variables.

The fact that multiple meteorological variables, and factors such as vulnerability, exposure, and adaptation (Huggel et al. 2013; IPCC 2012) influenced the public health and other outcomes of the 2006 severe heat wave suggests that a multivariate approach is required to assess the impact of this event (Fischer and Knutti 2012). High humidity heat waves, such as the 2006 event, have been found to be especially dangerous, accounting for $66 \%$ of hospitalizations associated with heat waves in the Central Valley (Guirguis et al. 2014). Unlike locations such as the eastern US and southeast Europe, the Central Valley is usually very dry during the summer and the model tends to favor high heat and low humidity values for most simulations. However, simulations do show markedly warmer temperatures in the $2000 \mathrm{~s}$ are the main driving factor in heat stress (Supplementary Fig. 3).

\section{Concluding remarks}

In the study by Thompson and Otto (2015), it is argued that PEA can serve as a basis for loss and damage on the international stage in accordance with the Warsaw International Mechanism for Loss and Damage (WIM). In this study, this notion is extended further to address climate justice within a developed nation like the United States. Here, PEA is used to examine the influence of anthropogenic heat-trapping gases on variables relevant to the public health sector, where the literature finds a strong link between extreme heat and vulnerable populations. During the July 2006 heat wave, for example, disadvantaged communities in the Central Valley of California were disproportionally affected (Knowlton et al. 2009). 
The model analysis suggests a strong link between rising temperature extremes and increasing levels of heat-trapping gases in the atmosphere when simulations with and without anthropogenic emissions are compared. Even more noteworthy are the marked increases in low temperatures in the observational record, decreasing the diurnal temperature range which can now be attributed to human activities (Stone and Weaver 2002). Being able to robustly attribute an increase in heat stress to human induced climate change is only one step away from attributing excessive deaths in a particular heat wave, highlighting the societal importance of these kinds of attribution studies and the need to further refine the method in future attribution work. These refinements include improvements for the inclusion of public health planning and adaptation actions taken prior to an event, socioeconomic demographics, and other human systems information (Hansen et al. 2015).

There is a question, however, as to which parties would be responsible for reparations or adaptation costs within the United States. It has been argued that this cost should not be taken up solely by the general public through taxation (Allen 2003). Instead, a different route can be taken if multinational corporations that extract carbon from the ground are included in the conversation as accountable for the impacts of climate change (Heede 2014). Thus, PEA can be focused more directly on changes in the environment incurred by carbon pollution traceable to major industrial carbon producers, allowing for policy-makers within developed nations to consider compensation and adaptation without solely relying on public funds.

Acknowledgments This research was supported by the Postdocs Applying Climate Expertise (PACE) Fellowship Program, partially funded by the NOAA Climate Program Office and administered by the UCAR Visiting Scientist Programs, Energy Foundation, Fresh Sound Foundation, The Grantham Foundation for the Protection of the Environment, Kendall Fellows Science Program (Union of Concerned Scientists), Mertz Gilmore Foundation, V. Kann Rasmussen Foundation and the Wallace Global Fund. We'd like to thank Ken Kunkel of the National Climatic Data Center for his assistance with the observational analysis and Brenda Ekwurzel of the Union of Concerned Scientists for technical editing.

Open Access This article is distributed under the terms of the Creative Commons Attribution 4.0 International License (http://creativecommons.org/licenses/by/4.0/), which permits unrestricted use, distribution, and reproduction in any medium, provided you give appropriate credit to the original author(s) and the source, provide a link to the Creative Commons license, and indicate if changes were made.

\section{References}

Allen MR (1999) Do-it-yourself climate prediction. Nature 401:642

Allen MR (2003) Liability for climate change. Nature 421:891

Bumbaco KA, Dello KD, Bond NA (2013) History of pacific northwest heat waves: synoptic pattern and trends. J Appl Meteorol Climatol 52:1618-1631. doi:10.1175/JAMC-D-12-094.1

California Department of Health Services (2007) Review of July 2006 Heat Wave Related Fatalities in California. Sacramento, CA: California Department of Health Services, Epidemiology and Prevention for Injury Control Branch

Cook BI, Miller RL, Seager R (2009) Amplification of the North American "dust bowl" drought through humaninduced land degradation. Proc Natl Acad Sci 106:4997-5001

Donlon CJ, Martin M, Stark JD, Roberts-Jones J, Fiedler E, Wimmer W (2011) The operational Sea surface temperature and Sea Ice analysis (OSTIA). Remote Sens Environ. doi:10.1016/j.rse.2010.10.017 2011

Dulière V, Zhang Y, Salathé EP (2011) Extreme precipitation and temperature over the U.S. Pacific northwest: a comparison between observations, reanalysis data, and regional models. J Clim 24:1950-1964

Fischer E, Knutti R (2012) Robust projections of combined humidity and temperature extremes. Nat Clim Chang 3:126-130

Fischer EM, Oleson KW, Lawrence DM (2012) Contrasting urban and rural heat stress responses to climate change. Geophys Res Lett 39(3), L03705. doi:10.1029/2011GL050576 
Gershunov A, Cayan DR, Iacobellis SF (2009) The great 2006 heat wave over California and Nevada: signal of an increasing trend. J Clim 22(23):6181-6203

Greene JS, Kalkstein LS (1996) Quantitative analysis of summer air masses in the eastern United States and an application to human mortality. Clim Res 7:43-53

Guirguis K, Gershunov A, Tardy A, Basu R (2014) The impact of recent heat waves on human health in California. J Appl Meteorol Climatol 53:3-19. doi:10.1175/JAMC-D-13-0130.1

Hajat S, Kosatky T (2010) Heat-related mortality: a review and exploration of heterogeneity. J Epidemiol Community Health 64(9):753-760

Hansen G, Stone D, Auffhammer M, Huggel C, and Cramer W (2015) Linking local impacts to changes in climate: a guide to attribution. Regional Environmental Change, 1436-3798. 10.1007/s10113-015-0760-y

Heede R (2014) Tracing anthropogenic carbon dioxide and methane emissions to fossil fuel and cement producers, 1854-2010. Clim Chang 122(1-2):229-241

Huggel C, Stone D, Auffhammer M, Hansen G (2013) Loss and damage attribution. Nat Clim Chang 3(8):694-696

IPCC (2012) Summary for Policymakers. In: Field CB, Barros V, Stocker T, Dahe Q

James R, Otto FEL, Parker H, Boyd E, Cornforth R, Mitchell D, Allen MR (2014) Characterizing loss and damage from climate change. Nat Clim Chang 4:938-939. doi:10.1038/nclimate2411

Jones RG, Noguer M, Hassel DC, Hudson D, Wilson SS, Jenkins GJ, Mitchell JFB (2004) Generating high resolution climate change scenarios using PRECIS. Met Office Hadley Centre Rep. pp 40

Kalkstein LS, Jamason PF, Greene JS, Libby J, Robinson L (1996) The Philadelphia hot weather-health watch/ warning system: development and application. Bull Am Meteorol Soc 77(7):1519-1528

Knowlton K, Rotkin-Ellman M, King G, Margolis HG, Smith D, Solomon G, Trent R, English P (2009) The 2006 California heat wave: impacts on hospitalizations and emergency department visits. Environ. Health Perspect 117:61-67

Kunkel KE, Bromirski PD, Brooks HE, Cavazos T, Douglas AV, Easterling DR (2008) Ch. 2: Observed changes in weather and climate extremes. Weather and Climate Extremes in a Changing Climate. Regions of Focus: North American, Hawaii, Caribbean, and U. S. Pacific Islands. Washington, D. C.: U. S. Climate Change Science Program and the Subcommittee on Global Change Research, T. R. Karl, G. A. Meehl, C. D. Miller, S. J. Hassol, A. M. Waple, and W. L. Murray, Eds.

Leiserowitz A, Akerlof K (2010) Race, Ethnicity and Public Responses to Climate Change. Yale University and George Mason University. New Haven, CT: Yale Project on Climate Change. http://environment.yale.edu/ uploads/RaceEthnicity2010.pdf

Lobell D, Bonfils C, Duffy PB (2007) Climate change uncertainty for daily minimum and maximum temperatures: a model intercomparison. Geophys Res Lett 34, L05715. doi:10.1029/2006GL028726

Luber G, McGeehin M (2008) Climate change and extreme heat events. Am J Prev Med 35(5):429-435

Massey N, Aina T, Rye C, Otto F, Wilson S, Jones R, Allen M (2012) Have the odds of warm November temperatures and of cold December temperatures in central England changed? Bull Am Meteorol Soc 93: 1057-1059

Massey N, Jones R, Otto FEL, Aina T, Wilson S, Murphy JM, Hassell D, Yamazaki YH, Allen MR (2014) weather@home - development and validation of a very large ensemble modelling system for probabilistic event attribution. QJR Met Soc DOI: 10.1002/qj.2455

Mastrangelo G, Hajat S, Fadda E, Buja A, Fedeli U, Spolaore P (2006) Contrasting patterns of hospital admissions and mortality during heat waves: Are deaths from circulatory disease a real excess or an artifact? Med Hypotheses 66(5):1025-1028

Menne MJ, Williams CN, Vose RS (2009) The US historical climatology network monthly temperature data, version 2. Bull Am Meteorol Soc 90:993-1007

Mote PW, Allen MR, Jones RG, Li S, Mera R, Rupp DE, Salahuddin A, Vickers D (2015) Superensemble regional climate modeling for the western US. Bull Amer Meteor Soc. doi:10.1175/BAMS-D-14-00090.1

O’Neill MS, Zanobetti A, Schwartz J (2005) Disparities by race in heat-related mortality in four U.S. cities: the role of air conditioning prevalence. J Urban Health 82(2):191-197

Otto FEL, Massey N, van Oldenborgh GJ, Jones RG, Allen MR (2013) Reconciling two approaches to attribution of the 2010 Russian heat wave. Geophys Res Lett 39, L04702. doi:10.1029/2011GL050422

Pall P, Aina T, Stone DA, Stott PA, Nozawa T, Hilberts AGJ, Lohmann D, Allen MR (2011) Anthropogenic greenhouse gas contribution to flood risk in England and wales in autumn 2000. Nature 470:382-385. doi: 10.1038/nature09762

Rayner NA, Parker DE, Horton EB, Folland CK, Alexander LV, Rowell DP, Kent EC, Kaplan A (2003) Global analyses of sea surface temperature, sea ice, and night marine air temperature since the late nineteenth century. J Geophys Res 108:4407. doi:10.1029/2002JD002670

Rupp DE, Li S, Massey N, Sparrow SN, Mote PW, Allen M (2015) Anthropogenic influence on the changing likelihood of an exceptionally warm summer in Texas, 2011. Geophys Res Lett 42:2392-2400. doi:10.1002/ 2014GL062683 
Schaller N, Otto FEL, van Oldenborgh GJ, Massey NR, Sparrow S, Allan MR (2014) The heavy precipitation event of May-june 2013 in the upper Danube and Elbe basins. Bull Am Meteorol Soc 95(9):S69-S72

Sippel S, Otto FEL (2014) Beyond climatological extremes - assessing how the odds of hydrometeorological extreme events in South-East Europe change in a warming climate. Clim Chang. doi:10.1007/s10584-0141153-9

Stone D and Weaver AJ (2002) Daily maximum and minimum temperature trends in a climate model Geophysical Research Letters 29. 10.1029/2001GL014556

Thompson A, Otto F (2015) Ethical and normative implications of weather event attribution for policy discussions concerning loss and damage. Clim Chang. doi:10.1007/s10584-015-1433-Z

Walsh J, Wuebbles D, Hayhoe K, Kossin J, Kunkel K, Stephens G, Thorne P, Vose R, Wehner M, Willis J, Anderson D, Doney S, Feely R, Hennon P, Kharin V, Knutson T, Landerer F, Lenton T, Kennedy J, Somerville R (2014) Ch. 2: Our Changing Climate. Climate Change Impacts in the United States: The Third National Climate Assessment, Melillo JM, Richmond T, Yohe GW, Eds., U.S. Global Change Research Program 19-67. doi:10.7930/J0KW5CXT

Wang F, Liu Z, Notaro M (2013) Extracting the dominant SST modes impacting north America's observed climate. J Clim 26:5434-5452

White-Newsome JL, O’Neill MS, Gronlund CJ, Sunbury TM, Brines SJ, Parker E et al (2009) Climate change, heat waves and environmental justice: advancing knowledge and action. Environ Justice 2(4):197-205

White-Newsome JL, Ekwurzel B, Baer-Schultz M, Ebi KL, O’Neill MS, Anderson GB (2014) Survey of countylevel heat preparedness and response to the 2011 summer heat in 30 U.S. States. Environ Health Perspect 122(6):573-579

Zhang Y, Dulière V, Mote PW, Salathe EP (2009) Evaluation of WRF and HadRM mesoscale climate simulations over the United States pacific northwest. J Clim 22:5511-5526 